\title{
AVALIAÇÃO DO CUSTO ENERGÉTICO DE DIFERENTES OPERAÇÕES AGRÍCOLAS MECANIZADAS
}

\author{
Evaluation of the energetic cost in different mechanized agricultural operations
}

\author{
Haroldo Carlos Fernandes ${ }^{1}$, João Cleber Modernel da Silveira ${ }^{2}$, Paula Cristina Natalino Rinaldi ${ }^{3}$
}

\begin{abstract}
RESUMO
Com o propósito de aumentar a eficiência de uso de insumos energéticos utilizados na agricultura tropical, procurou-se determinar o custo energético ( $\left.\mathrm{MJ} \mathrm{ha}^{-1}\right)$ das principais operações agrícolas mecanizadas em quatro sistemas de preparo do solo para a semeadura do milho e quantificar sua possível redução, utilizando os sistemas de preparo conservacionistas, em relação ao sistema convencional. O experimento foi conduzido na Universidade Federal de Viçosa - UFV. O delineamento experimental foi em parcelas subdivididas com quatro tratamentos e nove repetições, totalizando 36 parcelas experimentais. Foram avaliadas a densidade do solo, teor de água do solo e resistência do solo a penetração, o consumo de combustível e o custo energético. O plantio direto foi o sistema que proporcionou menor consumo de combustível, seguido pelo sistema de cultivo mínimo com grade de disco leve, preparo reduzido e preparo convencional, respectivamente. O plantio direto teve um custo energético de 52,72\% do custo do sistema convencional e o cultivo mínimo foi de $77,52 \%$, possibilitando economizar entre 1216,51 e $578,39 \mathrm{MJ} \mathrm{ha}^{-1}$, respectivamente, equivalente a 25,45 e $12,10 \mathrm{~L}$ de óleo diesel para cada hectare trabalhado.
\end{abstract}

Termos para indexação: Plantio direto, preparo do solo, consumo de combustível, energia.

\begin{abstract}
This study was carried out to increase the efficiency of energy inputs used in tropical agriculture, so the energy cost (MJ ha-1) of the main mechanized agricultural operations was determined in four soil preparation systems for seeding of maize. In addition, the possible reduction of this cost by the conservationist preparation systems was quantified, relative to the conventional system. The experiment was conducted in the Universidade Federal de Viçosa- MG, by using the split-plot design with four treatments and nine replicates, total of 36 experimental plots. The following variables were analyzed: soil density, soil water content, soil resistance to penetration, fuel consumption and energy cost. The no-till cropping provided the lowest fuel consumption, followed by the minimum cropping system with light-disk grate, the reduced preparation and the conventional one. The energy cost of the no-till planting was $52.72 \%$ the cost of the conventional system, where as the minimum cropping was $77.52 \%$, therefore turning possible to save between 1216.51 and $578.39 \mathrm{MJ} \mathrm{ha}^{-1}$, respectively, which corresponds to 25.45 and $12.10 \mathrm{~L}$ the diesel oil in each hectare.
\end{abstract}

Index terms: No-till planting, soil preparation, fuel consumption, energy.

(Recebido em 23 de agosto de 2006 e aprovado em 11 de abril de 2007)

\section{INTRODUÇÃO}

A introdução da máquina a vapor, do motor de combustão interna e do motor elétrico acentuou o uso da energia, em formas progressivamente sofisticadas, no sentido de serem mais gerenciadas. Com o desenvolvimento de outros sistemas de produção, como a indústria química, a agricultura passou a ser assistida também por energia embutida nos fertilizantes, pesticidas, combustíveis, cuja produção foi facilitada pela existência de outros recursos naturais, como os nitratos, os fosfatos, etc. Em regiões essencialmente agrícolas, neste caso citam-se os países da América do Sul e do Norte, observaram redução do seu potencial de produção, requerendo quantidades cada vez maiores de energia para manter a população crescente. É previsível que a mesma seqüência de evolução venha a ser percorrida pela agricultura brasileira, na qual a demanda de energia cresce mais depressa do que na indústria.

A agricultura tropical tem um importante peso na economia mundial, sendo o suporte da alimentação humana e animal, pois constitui a matéria prima da agroindústria, indústria química e indústria alimentícia.

Os prejuízos que o uso irracional da maquinaria agrícola traz ao ambiente são conhecidos, por isso, a tendência mundial está direcionada ao uso de sistemas conservacionistas na agricultura mecanizada, com uma alternativa de minimizar os danos ao solo, atmosfera, plantas e ao próprio homem.

${ }^{1}$ Engenheiro Agrícola, Doutor em Energia na Agricultura, Professor Associado - Departamento de Engenharia Agrícola/DEA - Universidade Federal de Viçosa/UFV - Avenida Ph. Rolfs, s/n - Campus Universitário - 36570-000 - haroldo@ufv.br

Engenheiro Agrícola, Doutor em Energia Agrícola - Departamento de Engenharia Agrícola/DEA - Universidade Federal de Viçosa/UFV - Avenida Ph. Rolfs, s/n - Campus Universitário - 36570-000 - jcmodernel@uol.com.br

${ }^{3}$ Engenheira Agrícola, Doutoranda em Engenharia Agrícola - Departamento de Engenharia Agrícola/DEA - Universidade Federal de Viçosa/UFV _ Avenida Ph. Rolfs, s/n - Campus Universitário - 36570-000 - pcnrinaldi@yahoo.com.br 
As estratégias de manejo de solos, segundo Fernandes et al. (2004), têm sido submetidas a significativas remodelações, face às novas informações, tendências e conhecimentos recentemente gerados dentro do enfoque sistêmico de produção. Nesse contexto, Mion (2002) afirma que o plantio direto, adequadamente conduzido, pode contribuir significativamente para tal feito, pois, envolvem a interação entre máquina, solo, clima, atmosfera e todos os organismos presentes no sistema. Inclui-se aí a redução do consumo de combustível, custos, entre outros.

Os solos brasileiros segundo Dallmeyer (1994) são na maioria, preparados mecanicamente com o uso de ferramentas que cortam, rompem e desestruturam o perfil do solo, por meio de arados, grades, enxadas rotativas e outros instrumentos com elevadas compressões sobre o mesmo, e que o uso contínuo de equipamentos de preparo constituídos por discos favorece a ocorrência de erosão, agravada pela degradação física do solo, podendo aparecer crostas superficiais e compactação abaixo das camadas subsuperfícial do solo.

Pesquisas têm sido realizadas com o intuito de buscar alternativas que atenuem os danos causados pelo preparo excessivo do solo, utilizando técnicas, como o plantio direto e o cultivo mínimo.

Dos debates estabelecidos nos últimos anos sobre a questão energética no Brasil, pouca importância se deu ao balanço energético dos sistemas produtivos. Considerações maiores têm sido efetuadas na busca por novas fontes, a partir de culturas com alto potencial de produção calórica. $\mathrm{O}$ conhecimento da relação produção/ consumo de energia, tanto quanto a análise econômica, é instrumental básico para elaboração de políticas que definam a quantidade de calorias e proteínas no consumo interno, exportação ou na transformação em combustíveis, permitindo prever o nível de dependência do País nessa área (CARMO \& COMITRE, 1991; CARMO et al., 1988).

O custo da maquinaria agrícola, fundamentalmente o combustível, segundo Ibañez \& Rojas (1994) varia entre 35 a $45 \%$ do custo total de produção. Entretanto, várias pesquisas têm estabelecido que o custo energético, especificamente o combustível e máquinas, representam alta porcentagem do custo energético total de produção na agricultura empresarial (FAO, 1990; FLUCK, 1981).

O balanço energético visa a estabelecer os fluxos de energia, identificando sua demanda total e eficiência, refletida pelo ganho líquido de energia e pela relação saída/ entrada, além da quantidade necessária para produzir ou processar um quilograma de determinado produto. Nesse processo, quantificam-se todos os insumos utilizados e produzidos que são transformados em unidades de energia.
A determinação da eficiência energética é importante instrumento no monitoramento da sustentabilidade da agricultura ante o uso de fontes de energia não-renováveis (BUENO et al., 2000).

Castro (1989) e Derpsch (1991) afirmam que o escarificador e suas qualidades em relação ao preparo conservacionista do solo são pouco conhecidos entre os agricultores do Brasil. Estes autores salientam a elevada capacidade de trabalho e a economia de combustível proporcionada pelo escarificador, quando comparado com o arado.

Siqueira et al. (1999) estimaram o balanço de energia na implantação de plantas de cobertura do solo (aveia preta, nabo forrageiro e tremoço azul), em preparo de solo convencional. Concluíram que, para a implantação e manejo da aveia e do nabo, o maior consumo de energia foi com combustível e fertilizantes; e, no caso do tremoço, foi com sementes e combustível.

Neste trabalho, objetivou-se foi determinar o custo energético das principais operações agrícolas mecanizadas em quatro métodos de preparo e semeadura do milho, quantificar a possível redução utilizando os sistemas de preparo conservacionistas em relação ao sistema convencional, partindo da hipótese de que é possível a economia de energia usando o preparo conservacionista.

\section{MATERIAL E MÉTODOS}

$\mathrm{O}$ experimento foi conduzido em área experimental da Universidade Federal de Viçosa (UFV), Viçosa, MG. A área experimental situa-se a $20^{\circ} 45^{\prime} 20^{\prime \prime} \mathrm{S}$ e a $42^{\circ} 52^{\prime} 40^{\prime \prime} \mathrm{W}$ (Gr), com altitude entre 600 e $700 \mathrm{~m}$. Caracteriza-se climaticamente por temperatura média anual de $19^{\circ} \mathrm{C}$ e precipitação média anual de 1300 a 1400 mm, concentrada, principalmente, no período de outubro a março. A umidade relativa média anual do ar estava entre 80 e $85 \%$ com temperatura média nesse período de $23^{\circ} \mathrm{C}$.

$\mathrm{O}$ experimento foi realizado em um solo Argisolo Vermelho-Amarelo (EMBRAPA, 1999), fase terraço. A área experimental era de aproximadamente de 1,0 ha, com declividade media de $2 \%$, com $100 \%$ coberta vegetação densa, predominando o capim-angola. Cada parcela experimental ocupou uma área de $80 \mathrm{~m}^{2}$, sendo $20 \mathrm{~m}$ de comprimento e $4 \mathrm{~m}$ de largura, agrupada em blocos separados por faixas de $1 \mathrm{~m}$ de largura. As parcelas foram separadas nos seus extremos longitudinais por faixas de $10 \mathrm{~m}$, para a realização das manobras e estabilização da velocidade dos conjuntos agrícolas.

$\mathrm{O}$ experimento foi estruturado em parcelas subdivididas, utilizando-se nove blocos com quatro parcelas cada um, totalizando 36 parcelas experimentais, 
avaliando-se nas mesmas a densidade do solo, o teor de água no solo, segundo Embrapa (1997), resistência do solo à penetração, conforme a norma ASAE S313.2 (ASAE, 1990), o consumo de combustível e o custo energético das operações.

Os sistemas de preparo e semeadura utilizados para a realização do experimento, constaram de preparo convencional (PC) com aração, gradagem e semeadura, utilizando uma semeadora convencional; cultivo mínimo (PR) com aplicação de herbicida, escarificação e semeadura com semeadora convencional; cultivo mínimo (CM) com aplicação de herbicida, grade de disco leve com $50 \%$ de abertura do ângulo de travamento, para o mínimo revolvimento do solo, e semeadura com semeadora convencional; e plantio direto (PD) com aplicação de herbicida e semeadura, utilizando uma semeadora de plantio direto. Na aplicação de herbicida para os tratamentos PR; CM e PD, foi utilizado o herbicida Glifosato para dessecação na dosagem de 1,5 $\mathrm{L} \mathrm{ha}^{-1}$.

A quantidade de matéria seca sobre a superfície foi determinada coletando-se o material vegetal existente dentro de um amostrador de chapa de aço de $30 \times 30 \mathrm{~cm}$ lançado ao acaso na superfície do solo. $\mathrm{O}$ material coletado foi seco em estufa com circulação forçada até a desidratação total para determinação de sua massa.

Foi utilizado um trator $4 \times 2$ TDA com potência máxima de $48 \mathrm{~kW}(65 \mathrm{cv})$ no motor a $2000 \mathrm{rpm}$ e massa de $3150 \mathrm{~kg}$.

Os implementos e máquinas utilizados na condução do experimento constaram de arado reversível com três discos lisos de 28 " x 3/16" e $540 \mathrm{~kg}$ de massa; grade leve com 32 discos e $690 \mathrm{~kg}$ de massa; vibro escarificador de 6 hastes, $356 \mathrm{~kg}$ de massa; pulverizador de barras, $450 \mathrm{~L} \mathrm{de}$ capacidade e $198 \mathrm{~kg}$ de massa; grade leve de $1250 \mathrm{~kg}$ de massa, 20 discos; semeadora-adubadora convencional com 3 unidades de semeadura para grãos graúdos com massa de $780 \mathrm{~kg}$ e uma semeadora-adubadora de plantio direto com 3 unidades de semeadura com massa de $870 \mathrm{~kg}$. As grades leves foram classificadas segundo Stolf (1986).

Para determinar a velocidade de deslocamento do trator, foram utilizados um cronômetro eletrônico, uma trena de $50 \mathrm{~m}$ de comprimento e, estacas. Todas as operações foram realizadas com o motor do trator a $1600 \mathrm{rpm}$ estabilizadas, e na marcha III R baixa. A rotação e marcha adotada foram utilizadas de acordo com as recomendações do fabricante e por atenderem à demanda dos equipamentos utilizados.

A patinagem dos rodados motrizes do trator, foi determinada considerando o tempo de deslocamento do mesmo com o implemento levantado pelo sistema hidráulico sobre a área de trabalho e o tempo gasto na realização da atividade na mesma área

A capacidade de campo teórica dos conjuntos implemento-trator foi determinada, utilizando-se a equação 1:

$$
\mathrm{C}=\frac{\mathrm{V} \mathrm{L}}{10}
$$

em que:

$\mathrm{C}=$ capacidade de campo teórica do conjunto implementotrator, ha $\mathrm{h}^{-1}$.

$\mathrm{L}=$ largura de trabalho, $\mathrm{m}$;

$\mathrm{V}=$ velocidade de trabalho $\mathrm{m} \mathrm{s}^{-1}$.

O consumo de combustível foi determinado, utilizando um fluxômetro construído no Laboratório de Mecanização Agrícola da UFV, constituído por uma bureta de vidro que foi instalada no circuito de alimentação do trator, sendo seu funcionamento controlado por um registro de fluxo.

A potência necessária foi calculada utilizando-se o procedimento padrão proposto por Asae (1993), adaptado por Paneque et al. (1998).

Para determinar o custo energético de execução da operação, foi utilizado a metodologia proposta por Hetz \& Barrios (1997). Esta metodologia determina o custo de energia em $\mathrm{MJ} \mathrm{h}^{-1}$ adicionando a equação à energia encontrada nos materiais de construção, incluindo a fabricação, transporte, combustível, lubrificantes, reparações e manutenções e mão de obra necessária para operar os equipamentos.

A energia correspondente ao combustível utilizada foi calculada pela norma proposta por Asae (1993), e a energia correspondente a lubrificantes/filtros e reparações/ manutenção foi calculada segundo proposta de Fluck (1981), correspondendo a 5\% da energia do combustível e $129 \%$ da energia de materiais/fabricação, respectivamente, e o custo energético da mão de obra foi estabelecido segundo proposta de Fluck (1981). Os custos energéticos expressos em $\mathrm{MJ} \times \mathrm{h}^{-1}$ foram transformados a $\mathrm{MJ} \times \mathrm{ha}^{-1}$.

\section{RESULTADOS E DISCUSSÃO}

$\mathrm{Na}$ análise de variância do comportamento da densidade do solo, teor de água no solo e da resistência do solo à penetração, não apresentaram estatisticamente diferenças significativas entre os tratamentos ao nível de $5 \%$ de probabilidade, não sendo necessária a comparação das médias dos mesmos pelo teste de Tukey ao mesmo nível (5\%). A densidade do solo na área experimental onde se aplicou os quatro sistemas de preparo e semeadura para milho, teve um valor médio de $1,09 \mathrm{~kg} \mathrm{dm}^{-3}$, verificando-se 
boa uniformidade do solo na área em estudo. A umidade média do solo nas condições de campo, foi de $0,26 \mathrm{~kg} \mathrm{~kg}$ 1. O índice de cone médio para a umidade obtida foi de $0,97 \mathrm{MPa}$. Valores estes próximos aos obtidos por Reis (2000), na mesma área. A quantidade de massa seca vegetal existente nas parcelas experimentais foi $5,71 \mathrm{t} \mathrm{ha}^{-1}$.

A análise de variância do comportamento do consumo de combustível, de acordo com o teste F mostrouse significativa para os quatro sistemas de preparo do solo e semeadura do milho. O coeficiente de variação foi de $10,46 \%$, indicando boa precisão experimental para os dados analisados. Segundo Gomes (1985), em experimentos de campos, considera-se aceitável um coeficiente de variação aceitável de $20 \%$.

Ocorreram diferenças significativas, a $5 \%$ de probabilidade, para todos os sistemas de preparo. O plantio direto foi o sistema que consumiu a menor quantidade de combustível que os demais sistemas, com um valor de 8,9 $\mathrm{L} \mathrm{ha}^{-1}$, o que pode ser explicado, pois este sistema reduz significativamente o número de operações por hectare, seguido pelo cultivo mínimo com grade leve (14,3 $\left.\mathrm{L} \mathrm{ha}^{-1}\right)$, cultivo mínimo com vibro escarificador $\left(17,1 \mathrm{~L} \mathrm{ha}^{-1}\right)$ e preparo convencional (20,7 $\left.\mathrm{L} \mathrm{ha}^{-1}\right)$. Levien et al. (1999) obtiveram valores de 13,0; 12,9 e 12,3 $\mathrm{L} \mathrm{h}^{-1}$ de óleo diesel para semeadura em solo classificado como Nitossolo Vermelho Distrófico Latossólico, preparado pelo método convencional, reduzido (escarificação) e plantio direto, respectivamente.

Os resultados obtidos durante o experimento foram tabulados e submetidos à análise de variância. Para os casos em que o teste de $\mathrm{F}$ foi significativo, realizou-se o teste de comparação de médias pelo teste de Tukey $(\mathrm{p}<0,05)$.

A análise de variância do comportamento dos custos energéticos, principal objetivo deste trabalho, apresentou diferenças estatísticas significativas pelo teste de $\mathrm{F}$ entre os tratamentos dos quatros sistemas de preparo e semeadura do milho $(\mathrm{p}<0,01)$. O coeficiente de variação foi de $0,15 \%$, indicando ótima precisão experimental. De acordo com o teste de Tukey, ao nível de $5 \%$ de probabilidade, observa-se que os custos energéticos dos sistemas em estudos diferiram estatisticamente entre si.

$\mathrm{Na}$ Tabela 1 são apresentados os custos energéticos dos quatro sistemas de preparo e semeadura do milho.

Verifica-se para o preparo convencional (PC), preparo com cultivo mínimo com vibro escarificador (PR), preparo com cultivo mínimo com grade leve $(\mathrm{CM})$ e plantio direto (PD), custos médio de 2572,89; 2105,22; 1994,50 e $1356,38 \mathrm{MJ} \mathrm{ha}^{-1}$, respectivamente. Estes resultados demonstraram que o plantio direto e a utilização do cultivo mínimo para as operações agrícolas podem trazer inúmeros benefícios para a conservação do solo, menor degradação dos solos, menor mobilização do solo, conservação da macro e micro fauna, temperatura e umidade do solo, entre outros. Neste sentido, segundo Gassen \& Gassen (1996), resultados de estudos evidenciaram que em áreas extensas, o plantio direto, apresenta maiores vantagens na redução dos custos de produção ( $15 \%$ nos custos diretos, $60 \%$ no consumo de combustível, $50 \%$ no investimento de máquinas e $60 \%$ no consumo de força).

Tabela 1 - Custo energético dos quatros sistemas de preparo e semeadura do milho. Preparo Convencional (PC), Cultivo Mínimo (PR), com vibro escarificador, Cultivo Mínimo (CM) com grade leve, e Plantio direto (PD).

\begin{tabular}{lcccc}
\hline \multirow{2}{*}{ Operações } & \multicolumn{4}{c}{ Sistemas de preparo } \\
\cline { 2 - 4 } & PC & PR & CM & PD \\
\cline { 2 - 4 } & & \multicolumn{4}{c}{ Custo energético $\left(\mathrm{MJ} \mathrm{ha}^{-1}\right)$} & - \\
\hline Arado de disco & 1420,43 & - & - & - \\
Grade de disco & 573,80 & - & - & 815,85 \\
Pulverização & - & 818,03 & 816,06 & - \\
Grade leve & - & - & 656,24 & - \\
Vibro escarificador & - & 749,09 & - & 540,53 \\
Semeadura & 578,66 & 536,09 & 532,20 & 1356,38 \\
\hline Total & 2572,89 & 2105,22 & 1994,50 & 52,72 \\
\hline Percentagem total $(\%)$ & 100 & 81,82 & 77,52 & \\
\hline
\end{tabular}




\section{CONCLUSÕES}

Nas condições em que foi realizado o experimento e nos resultados obtidos, este trabalho possibilitou concluir que o sistema que apresentou menor consumo horário de combustível foi o plantio direto, seguido pelo cultivo mínimo (grade leve e vibro escarificador, respectivamente) e preparo convencional.

Os custos energéticos do sistema de plantio direto foram menores que os do sistema convencional em 52,72\%.

O preparo com cultivo mínimo (grade leve) com $77,52 \%$, proporcionou uma economia entre 1216,51 e 578,39 $\mathrm{MJ} \mathrm{ha}^{-1}$ respectivamente, o equivalente a 25,45 e $12,10 \mathrm{~L}$ de combustível para cada hectare trabalhado.

\section{REFERÊNCIAS BIBLIOGRÁFICAS}

AMERICAN SOCIETY OF AGRICULTURAL ENGINEERS. Agricultural engineers yearbook. Saint Joseph, 1993.

AMERICAN SOCIETY OF AGRICULTURAL ENGINEERS. ASAE 1990. Saint Joseph; Michigan, 1990.

BUENO, O. C.; CAMPOS, A. T.; CAMPOS, A. T. Balanço de energia e contabilização da radiação global: simulação e comparativo. Buenos Aires: Facultad de Agronomia, 2000.

CARMO, M. S.; COMITRE, V. Evolução do balanço energético nas culturas de soja e milho no Estado de São Paulo. In: CONGRESSO BRASILEIRO DE ECONOMIA E SOCIOLOGIA RURAL, 29., 1991, Campinas. Anais... Brasília, DF: Sociedade Brasileira de Economia e Sociologia Rural, 1991. p. 131-149.

CARMO, M. S.; COMITRE, V.; DULLEY, R. D. Balanço energético de sistemas de produção na agricultura alternativa. Agricultura em São Paulo, São Paulo, v. 35, n. 1, p. 87-97, 1988.

CASTRO, O. M. Preparo do solo para a cultura do milho. Campinas: Fundação Cargill, 1989. 41 p.

DALLMEYER, A. U. Avaliação energética e desempenho operacional de equipamentos de preparo do solo. 1994. 156 f. Tese. (Doutorado em Agronomia) - Universidade Estadual Paulista, Botucatu, 1994.

DERPSCH, R. Controle da erosão no Paraná, Brasil: sistemas de cobertura do solo, plantio direto e preparo conservacionista do solo. Eschborn: GTZ, 1991. 272 p.

EMPRESA BRASILEIRA DE PESQUISA AGROPECUARIA. Centro Nacional de Ciência do Solo.
Manual de métodos de análise de solo. Rio de Janeiro, 1997. Não paginado.

EMPRESA BRASILEIRA DE PESQUISA AGROPECUARIA. Sistema Brasileiro de classificação de solos. Rio de Janeiro, 1999.

FAO. Energy consumption and input output relation in field operations. Rome, 1990.

FERNANDES, H. C.; MODOLO, A. J.; OLIVEIRA, A. D. Adaptação de uma plantadora de batata para trabalhar em sistemas de plantio direto e cultivo mínimo. Engenharia na Agricultura, Viçosa, v. 12, n. 4, p. 247-259, 2004.

FLUCK, R. Net energy sequestered in agricultural labor. Transactions of the ASAE, Amsterdam, v. 24, n. 6, p. 1449$1455,1981$.

GASSEN, N. D.; GASSEN, F. R. Plantio direto: o caminha do futuro. Passo Fundo: Aldeia Sul, 1996. 207 p.

GOMES, F. P. Curso de estatística experimental. 11. ed. Piracicaba: Nobel, 1985. 466 p.

HETZ, E.; BARRIOS, A. Costo energético de las operaciones agrícolas mecanizadas más comunes en Chile. Agro Sur, Concepción, v. 24, n. 2, p. 146-161, 1997.

IBAÑEZ, M.; ROJAS, E. Costos de operación y producción por concepto de maquinaria agrícola. Concepción: Universidad Concepción, 1994. 58 p.

LEVIEN, R.; MARQUES, J. P.; BENEZ, S. H. Desempenho de uma semeadora adubadora de precisão, em semeadura de milho (Zea mays L.), sob diferentes formas de manejo do solo. In: CONGRESSO BRASILEIRO DE ENGENHARIA AGRÍCOLA, 28., 1999, Pelotas. Anais... Pelotas: Sociedade Brasileira de Engenharia Agrícola, 1999. CD-ROM.

MION, R. L. Desenvolvimento de equipamento para ensaio a campo de ferramentas de rompimento do solo testado com mecanismos de abertura de sulcos de semeadoras. 2002. 96 f. Dissertação (Doutorado em Agronomia) Universidade Estadual Paulista, Botucatu, 2002.

PANEQUE, P.; MARRERO, E.; DE LAS CUEVAS, H. Determinación de la fuente energética para las labores mecanizadas de los cítricos. La Habana, Cuba. Revista Ciências Técnicas Agropecuárias, [S.1.], v. 7, n. 3, p. 2532, 1998. 
REIS, E. F. Inter-relação solo-semente com duas semeadorasadubadoras de plantio direto, em diferentes umidades de um solo argiloso. 2000. 51 f. Dissertação (Mestrado em Engenharia Agrícola) - Universidade Federal de Viçosa, Viçosa, 2000.

SIQUEIRA, R.; GAMERO, C. A.; BOLLER, W. Balanço de energia na implantação e manejo de plantas de cobertura do solo. Engenharia Agrícola, Jaboticabal, v. 19, n. 1, p. 80-89, 1999.

STOLF, R. Grades: sua classificação e função na cultura canavieira. Revista Álcool \& Açúcar, Piracicaba, n. 28, maio/jun. 1986. 